\title{
L'alumnat de cicle inicial de primària millora la concentració jugant a tennis taula
}

\author{
Míriam Segura-Meix ${ }^{1}$ (D), Mònica Moratalla-Blanch² \\ Article d'Estudis i Tendències. Rebut: 19/01/2021. Acceptat: 05/03/2021. Publicat en avançada: 17/05/2021. Publicat: 01/07/2021
}

\begin{abstract}
Resum
INTRODUCCIÓ. La concentració de l'alumnat a l'escola és motiu d’ocupació i preocupació dels docents. Són molts els professionals que intenten trobar estratègies acadèmiques adequades per augmentar-la i permetre a l'alumnat assolir un nivell d'aprenentatge superior $\mathrm{i}$ amb menys temps.
\end{abstract}

MÈTODE. L'estudi, realitzat a partir del test CARAS-R de Thurstone i Yela de 2012, ha permès verificar i donar suport a la hipòtesi plantejada per mitjà d'una metodologia quantitativa. Al mateix temps s'ha analitzat l'índex de control de la impulsivitat i s'ha vist una millora en el seu grau de reflexió davant les situacions quotidianes.

RESULTATS. La concentració de l'alumnat participant en la recerca ha augmentat un $27,98 \%$ en el grup experimental (26 participants) i un $5,05 \%$ en el grup de control.

DISCUSSIÓ. En aquesta recerca hem demostrat que la pràctica del tennis taula ha contribuït a la millora de la concentració dels infants que han estat sotmesos a una proposta d'introducció d'aquest esport respecte a un grup de control amb les mateixes característiques. Finalment, es planteja la possibilitat de fer un estudi ampliant la mostra i allargant-lo en el temps per analitzar els resultats a llarg termini.

Paraules clau

Atenció; Concentració; Esport; Índex de control de la impulsivitat; Tennis taula.

Dades de les autores

${ }^{1}$ Universitat Rovira i Virgili, Espanya. Departament de Pedagogia, responsable de l'ensenyament de doble titulació de grau d'Educació Infantil i Educació Primària del Campus Terres de l’Ebre. Correu per a la correspondència: miriam.segura@urv.cat

${ }^{2}$ Mestra d'educació primària.

Referència recomanada

Segura-Meix, M., i Moratalla-Blanch, M. (2021). L'alumnat de cicle inicial de primària millora la concentració jugant a tennis taula. REIRE Revista d'Innovació i Recerca en Educació, 14(2), 1-16. https://doi.org/10.1344/reire2021.14.233386

(C) 2021 Les autores. Aquest article és d'accés obert subjecte a la llicència de Reconeixement 4.0 Internacional Creative Commons, la qual permet utilitzar, distribuir i reproduir per qualsevol mitjà sense restriccions sempre i quan se citi adequadament l'obra original. Per veure una còpia de la llicència, visiteu https://creativecommons.org/licenses/by/4.0/

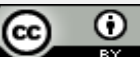


Título (castellano)

Los alumnos de ciclo inicial de Primaria mejoran su concentración jugando a tenis de mesa

\section{Resumen}

INTRODUCCIÓN. La falta de concentración del alumnado en la escuela es motivo de ocupación y preocupación de los docentes. Son muchos los profesionales que intentan encontrar estrategias académicas adecuadas para aumentarla y permitir al alumnado lograr un nivel de aprendizaje superior y en menos tiempo.

MÉTODO. El estudio, realizado a partir de la Test Caras-R de Thurstone y Yela de 2012, ha permitido verificar y apoyar la hipótesis planteada por medio de una metodología cuantitativa. Al mismo tiempo se ha analizado el índice de control de la impulsividad aportando una mejora en su grado de reflexión ante las situaciones cotidianas.

RESULTADOS. La concentración del alumnado que ha participado en la investigación ha aumentado un 27,98 \% en el grupo experimental (26 participantes) y un 5,05 \% en el de control.

DISCUSIÓN. En esta investigación hemos demostrado que la práctica del tenis de mesa ha contribuido en la mejora de la concentración de los niños que han sido sometidos a una propuesta de introducción de este deporte respecto un grupo control con las mismas características. Finalmente, se plantea la posibilidad de realizar un estudio ampliando la muestra y alargándolo en el tiempo para estudiar los resultados a largo plazo.

Palabras clave

Atención; Concentración; Deporte; Índice de Control de la Impulsividad; Tenis de mesa

\section{Title (English)}

Primary school students (key stage 2 ) improve their concentration by playing table tennis

\section{Abstract}

INTRODUCTION. The concentration levels of students in school are a matter for concern among teachers. Many professionals have tried to find adequate academic strategies for increasing students' concentration and thus enabling them to achieve a higher level of learning in a shorter time.

METHOD. The study, carried out using Thurstone and Yela's Faces-DPT published in 2012, applies a quantitative methodology to test and support the hypothesis. Analysis of the impulsivity control index showed an improvement in participants' degree of reflection in everyday situations

RESULTS. Concentration levels in the students who participated in the research increased by $27.98 \%$ in the experimental group ( 26 participants) and by $5.05 \%$ in the control group.

DISCUSSION. Playing table tennis helped to improve the concentration of children with respect to a control group with the same characteristics. The plan now is to conduct a broader study in a larger sample, over a longer time period, in order to study the long-term results.

\section{Keywords}

Attention; Concentration; Sport; Impulsivity control index; Table tennis 


\section{Introducció}

La manca de concentració per part de l'alumnat és una realitat en moltes escoles del país. En aquesta recerca ens hem plantejat analitzar si la pràctica del tennis taula ajuda l'alumnat a millorar els seus nivells de concentració. Palacios, Marchesi i Coll (2006) defineixen la concentració com aquella capacitat mental dels éssers humans per controlar, dirigir i mantenir l'atenció. Aquesta té un paper molt important, perquè és l'encarregada del desenvolupament de les tasques més bàsiques en el procés d'aprenentatge dels infants, com són l'escriptura, la lectura o el raonament, i posteriorment, en els més grans, l'estudi. Així doncs, la concentració es caracteritza per ser un estímul determinat que a partir de la pràctica i el treball es pot millorar. Per tant, implica capacitat de concentració i un estímul. Aquest últim pot ser un objecte o una acció que atregui l'atenció de la persona, i pot ser exogen o endogen, és a dir, pot prevenir del medi o del cos mateix de l'individu. Quan l'atenció es concentra, la percepció de l'objecte o de l'acció que es vol analitzar augmenta i adquireix més força per fixar-se a la nostra memòria.

Per tal de donar fruit a una millora de la concentració, s'utilitza l'atenció com una eina de treball de la qual es pot fer ús. Es coneix I'atenció com una habilitat que a partir de la pràctica, un entrenament constant i un desenvolupament evolutiu pot aconseguir un progrés en I'atenció plena. Segons García (2010) hi ha diferents criteris que es poden fer servir per classificar la concentració. Així doncs, parlem de concentració voluntària i concentració involuntària, tal com es pot veure a la figura 1.

\section{Figura 1}

Classificació de la concentració

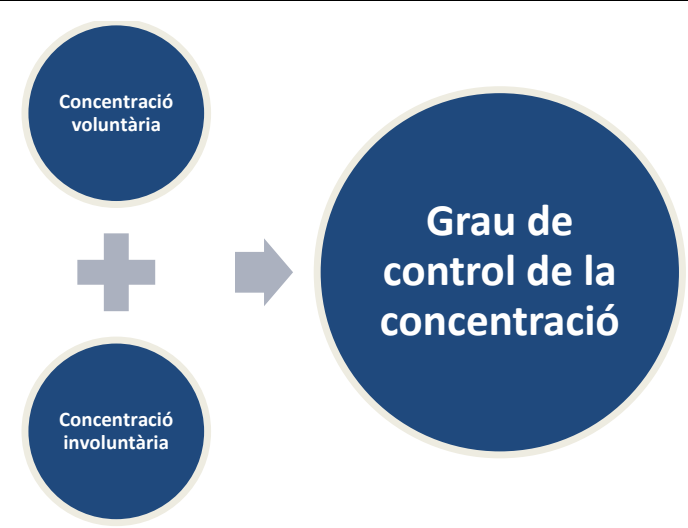

Font. Elaboració pròpia.

Per una banda, la concentració involuntària és aquella que es defineix per la presència d'objectes que apareixen davant de l'individu com una novetat i, per tant, actuen sobre els sentits per primer cop. En línies generals, la concentració involuntària està determinada per l'estat d'ànim en què es troba la persona. En conseqüència, en queda un record fixat a la memòria que lliga la situació viscuda amb l'estat d'ànim que genera aquesta situació. Un exemple d'aquesta característica és quan a un nen petit li cau la primera dent de llet: si en aquell moment li fa mal en guardarà un mal record i, per tant, la concentració involuntària anirà lligada al mal moment que va passar el nen aquell dia. Per l'altra, la concentració voluntària és aquella activitat que l'individu fa conscientment per assolir un objectiu concret. Quan la persona fa ús d'aquest tipus de concentració és perquè el cervell ja coneix aquesta mena d'estímuls i, consegüentment, està lligada i relacionada amb records i experiències passades. Per exemple, quan un nen ha d'estudiar nous conceptes sobre algun tema en concret, prèviament s'ha de concentrar en els coneixements que ja té adquirits sobre temes anteriors per després poder relacionar-los i seguir amb els nous aprenentatges. 
De vegades, la concentració es veu afectada per un seguit de factors que fan que aquesta disminueixi notablement, la qual cosa té un efecte, doncs, en la realització de la tasca marcada com a objecte d'estudi. Quan això passa, apareix el que es coneix com a falta de concentració, donada per quatre factors generals: la tensió, la fatiga, la distracció i els problemes personals. La tensió és un dels factors més influents en el procés de la distracció, perquè és necessària en el procés de la concentració. Quan un individu vol centrar tota la seva atenció en una activitat determinada, el cos requereix una tensió neuromuscular adequada a la situació. Si aquest tipus de tensió sobrepassa els llindars normals als quals el cos està acostumat, esdevé un factor que disminueix el poder de la concentració $i$, en conseqüència, la capacitat d'entendre l'objecte d'estudi. La tensió neuromuscular augmenta i interfereix en l'atenció, de manera que la persona és incapaç de concentrar-se per molt que hi hagi moments de descans. Ni la fatiga física ni la psicològica no són causes perdurables; la distracció sol ser el factor principal de la falta de concentració. S'entén com la disminució de la capacitat de concentració a causa de la presència al lloc d'estudi d'altres estímuls i de problemes personals o neguits (Martí i Marrugat, 2014).

Així doncs, l'atenció es pot definir com el mecanisme que permet centrar-nos en un sol estímul d'entre tots els que hi ha al voltant i ignorar-ne la resta. És el procés a través del qual se selecciona algun tipus d'estímul de l'ambient que ens envolta; el cos s'encarrega de demanar la tensió neuromuscular necessària que servirà per engegar el procés de la concentració.

L'atenció està condicionada a l'interès, sigui per les característiques de l'estímul (mida, color, forma, moviment, etc.), sigui per les pròpies motivacions. L'interès, doncs, està entrellaçat amb l'atenció, com l'atenció i la concentració. L'atenció involuntària és aquella en què no es posa intenció i que interromp qualsevol acció, com pot ser un soroll fort, una veu coneguda, una llum. L'atenció voluntària és la que requereix l'elecció i, per tant, suposa un esforç per lluitar entre el conflicte de l'atracció que exerceixen els altres estímuls i el que es necessita. Aquest tipus d'atenció és la indispensable per obtenir rendiment escolar i, per tant, la que es tractarà com a font d'estudi al llarg d'aquesta investigació. Recapitulant, doncs, l'atenció és la capacitat d'aplicar voluntàriament el coneixement a un objecte o activitat, tenir-lo en compte o en consideració, i la concentració és el procés psíquic que consisteix a centrar voluntàriament tota l'atenció de la ment en un objecte o activitat que s'estigui realitzant en aquell moment.

Per treballar la concentració és necessària la relaxació, entesa com l'estat de tranquil-litat física i psíquica que es manifesta espontàniament quan l'individu es troba en un moment de calma, d'absència d'estrès, excitació i altres alteracions mentals. Durant el procés de relaxació el cervell fa conscient el cos i avisa de qualsevol defecte o acció que està produint tensions. És llavors quan, per tal de no esgotar les energies de forma innecessària, demana que es relaxi.

És freqüent trobar a les aules un nombre elevat d'alumnes amb dificultats de concentració. Des de ben petits se'ls exigeix un aprenentatge elevat causat per la interferència constant d'elements nous a la vida, que solen generar dubtes i molts interrogants. Martí i Marrugat (2014) consideren que els motius d'aquesta pèrdua d'atenció es troben en factors múltiples com:

Canvis en la família, en l'economia, en la professió, en la feina, en la seguretat laboral; canvis de domicili, de ciutat o de país; canvis de benestar, en les tecnologies, en les noves xarxes socials; aparició de nous llenguatges i formes de comunicar-se; canvis en la informació transmesa i la seva veracitat, en els valors que transmet; canvis en els objectius de futur dels joves i no tan joves. (p. 13)

Per acabar, cal recordar que és important crear un àmbit tranquil amb una posició còmoda i relaxada per tal de centrar tota l'atenció en l'objecte d'estudi o d'interès. 
L'esport del tennis taula exigeix molta concentració. L'entrenament de les habilitats mentals és un dels factors més importants a tractar, i és per això que en psicologia de l'esport la concentració és objecte $\mathrm{d}$ 'anàlisi. Molts cops, abans de dur a terme una acció tècnica, els esportistes tendeixen a establir una sèrie de patrons repetitius (també anomenats rituals) que els permeten mantenir la concentració. Al tennis taula, però, també hi ha distraccions. Guallar i Pons (1994) classifiquen les distraccions que solen descriure els psicòlegs de l'esport en dos tipus: distraccions internes, que provenen de la persona mateixa i impedeixen centrar l'atenció en la feina que es vol fer, i distraccions externes, que fan referència a senyals irrellevants de l'entorn que impossibiliten una plena concentració i que poden ser de magnitud diversa, com ara el públic, factors meteorològics, sorolls o provocacions de l'adversari. Així doncs, s'estableix la relació entre concentració i rendiment, la qual cosa afirma que una concentració més eficient i sense distraccions contribuirà a una més alta probabilitat d'èxit esportiu.

\section{Figura 2}

Relació entre concentració i rendiment

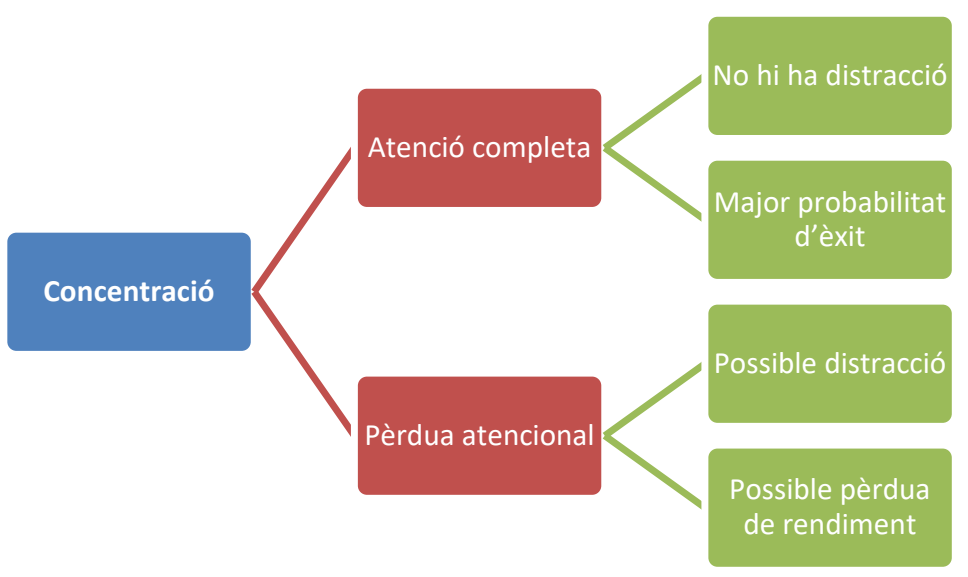

Font. Elaboració pròpia a partir de Guallar i Pons (1994).

Així mateix, altres investigadors com Weinberg i Gould (2010) parteixen d'una altra teoria que defensa que els esportistes amb més èxit esportiu tendeixen a distreure's menys. Tanmateix, afirmen que aquest tipus de jugadors són capaços de mantenir l'atenció sobre l'acció que volen realitzar sense preocupar-se tant pel resultat. Per tant, els ingredients fonamentals per a un alt nivell en la competició esportiva són la intensitat i la concentració. Centrant-nos en el tennis taula, es pot veure que és un esport que requereix una coordinació molt precisa per actuar amb rapidesa i tornar la pilota, que de vegades va a tanta velocitat que és difícil de veure. Aquesta coordinació estimula el cerebel, perquè la intensitat de joc exigeix un enfocament complet i una gran concentració per seguir el moviment de la pilota. El tennis taula és un esport molt complet pel que fa a la formació tant professional com personal de l'esportista i ajuda a la millora de la concentració, la coordinació i la velocitat.

\section{Objectius i marc metodològic}

Aquesta investigació ha seguit una línia de recerca basada en dues àrees de treball fonamentals en l'etapa escolar: la psicologia i l'esport. En la recerca presentada, d'acord amb Bisquerra (2016), hem utilitzat una metodologia quantitativa orientada a solucionar un dels problemes pràctics i presents cada dia a l'aula: la 
falta de concentració. L'objectiu general d'aquesta recerca ha estat millorar la concentració de l'alumnat, sigui a l'aula o en altres àmbits, a partir de la pràctica del tennis taula. Entre els objectius específics hi havia: potenciar l'interès dels nens i nenes pel tennis taula, establir millors relacions entre l'alumnat de la classe i conèixer l'índex d'impulsivitat davant els estímuls. La finalitat principal d'aquesta investigació era observar si realment el tennis taula aporta beneficis en el nivell de concentració de l'alumnat i si s'observava una evolució a l'aula. La hipòtesi de treball ha estat que els infants que juguen a tennis taula milloren els nivells de concentració, i l'hem posat a prova relacionant dues variables: sessions de pràctica de l'esport (variable independent) i concentració (variable dependent). La mostra objecte d'estudi han estat dos grups, un de control (26 participants) i un d'experimental (26 participants) de primer curs de cicle inicial d'una escola de les Terres de l'Ebre, Tarragona. Per a la recollida de dades s'ha emprat el test CARAS-R de Thurstone i Yela (2012). Aquesta prova, dissenyada per ser aplicada a nens i adolescents d'edats compreses entre els 6 i els 18 anys, ajuda a avaluar l'aptitud per percebre de forma ràpida i correcta les semblances i diferències i els patrons estimulants parcialment ordenats. A partir d'un grup de 60 elements gràfics en què cada un està format per tres dibuixos esquemàtics de cares amb boca, celles i cabells, els participants han de trobar el que té algun d'aquests trets diferent.

La prova es caracteritza per poder respondre a la discriminació visual d'elements que aparentment són iguals, i el fet d'observar la diferència que existeix entre les cares dona uns valors que es correlacionen positivament amb la intel-ligència general. Considerant el nombre d'encerts i errors comesos per qui fa el test, es poden obtenir unes puntuacions que faciliten l'índex de control de la impulsivitat i, per tant, es pot relacionar el rendiment de la seva concentració amb el tipus de resposta. Al corrector o mestre només li cal la plantilla de correcció i un cronòmetre per mesurar el temps: en 3 minuts s'ha d'intentar respondre correctament al màxim nombre possible de cares diferents. Un cop el test està resolt, el corrector ha d'anotar el nombre d'encerts (A) donant un punt a cada resposta correcta, els errors comesos comptant cada cara que no estigui ben assenyalada $(E)$, els encerts nets com a càlcul després d'haver restat el nombre d'errors al nombre d'encerts (A-E), i l'índex de control de la impulsivitat (ICI), que es calcula dividint el nombre d'encerts nets $(A-E)$ entre el nombre de respostes donades $(A+E)$. Per tal de facilitar la interpretació dels càlculs es multiplica el resultat final per 100 per eliminar els decimals.

El procés es va estructurar en tres fases: estat de la concentració inicial (pretest), proposta d'introducció i estat de la concentració final (posttest).

\section{Resultats}

Feta la intervenció i quantificats els resultats, obtenim unes primeres dades generals. El grup de control en el pretest ha assolit una puntuació de 416 punts i en el posttest 437, 21 punts més, la qual cosa representa un increment del 5,05\%. El grup experimental ha passat de 336 punts al pretest -partia de nivells més baixos- a 430 al posttest, un increment de 94 punts. Això suposa un augment de gairebé el $30 \%$, concretament $27,98 \%$.

Per extreure' $n$ correctament els resultats cal interpretar el test CARAS-R de Thurstone i Yela observant els enneatipus com a elements principals, ja que per mitjà d'una escala tipificada amb nou valors (de l'1 al 9) ens ajuda a expressar el nombre de desviacions típiques que s'allunya el resultat del test de la mitjana (taula $1)$. 
Taula 1

Criteris de classificació dels enneatipus

\begin{tabular}{ll} 
Enneatipus & Nivell \\
\hline 9 & Molt alt \\
8 & Alt \\
7 & Mitjà-alt \\
$4-5-6$ & Mitjà \\
3 & Mitjà-baix \\
2 & Baix \\
1 & Molt baix \\
\hline
\end{tabular}

D'aquesta manera es veu com un nombre més elevat indica una aptitud més alta. Tenint en compte aquests valors en què la mitjana és 5 i la desviació típica és 2 , les puntuacions entre 3 i 7 reflecteixen un rendiment dintre de la mitjana.

A fi d'analitzar l'eficàcia real dels participants del test hem tingut en compte els encerts nets, és a dir, els que resulten de restar dels encerts totals els errors comesos, perquè mostren una percepció més correcta de la realitat (eficàcia = encerts nets; encerts nets = encerts - errors). A aquest valor és correcte lligar-hi l'índex de control de la impulsivitat, ja que dona informació de la impulsivitat en les respostes de l'alumnat. Considerant aquests dos elements com a objecte d'estudi en la mostra, a la figura es pot veure com s'interpreta el valor resultant.

\section{Figura 3}

Estils de resposta obtinguts a partir de la relació eficàcia i l'ICI

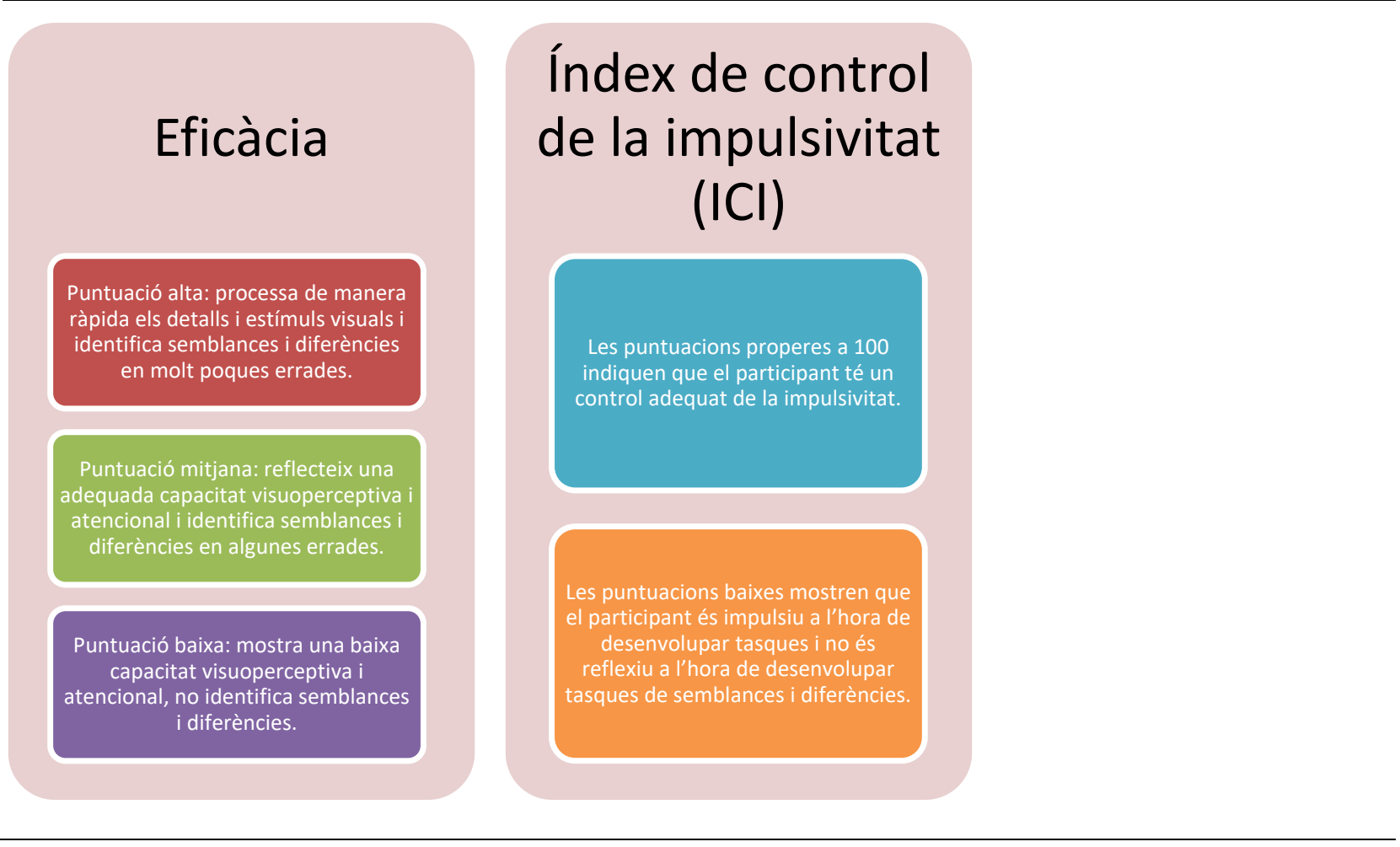

Font. Elaboració pròpia. 
A partir de les interpretacions anteriors és quan es pot observar la figura següent, que relaciona les dues variables d'una forma gràfica per tal de facilitar la comprensió.

\section{Figura 4}

Valors interpretatius dels resultats

\section{$+\mathbf{A}$}

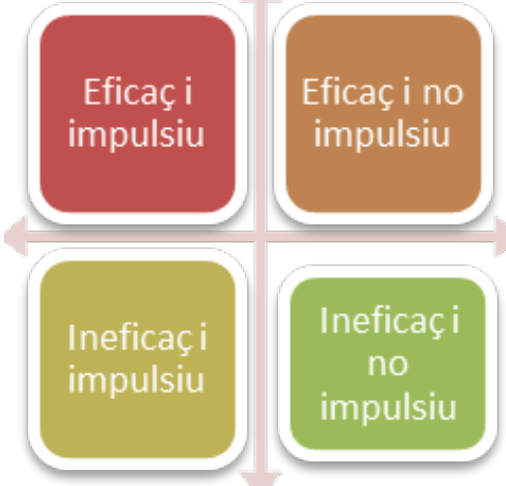

$+\mathbf{I C I}$

Font. Elaboració pròpia.

Aquesta relació es pot veure aplicada al buidatge de les dades obtingudes amb els tests realitzats a la mostra. La taula que recull els resultats del grup experimental es troba a l'annex 1 i els del grup de control, a l'annex 2.

Observant els resultats del test i les dades recollides, podem observar a la figura següent la comparativa inicial i final dels encerts nets del grup experimental juntament amb l'enneatipus corresponent.

\section{Figura 5}

Encerts nets del grup experimental

\section{Encerts nets $(A-E)$, grup experimental}

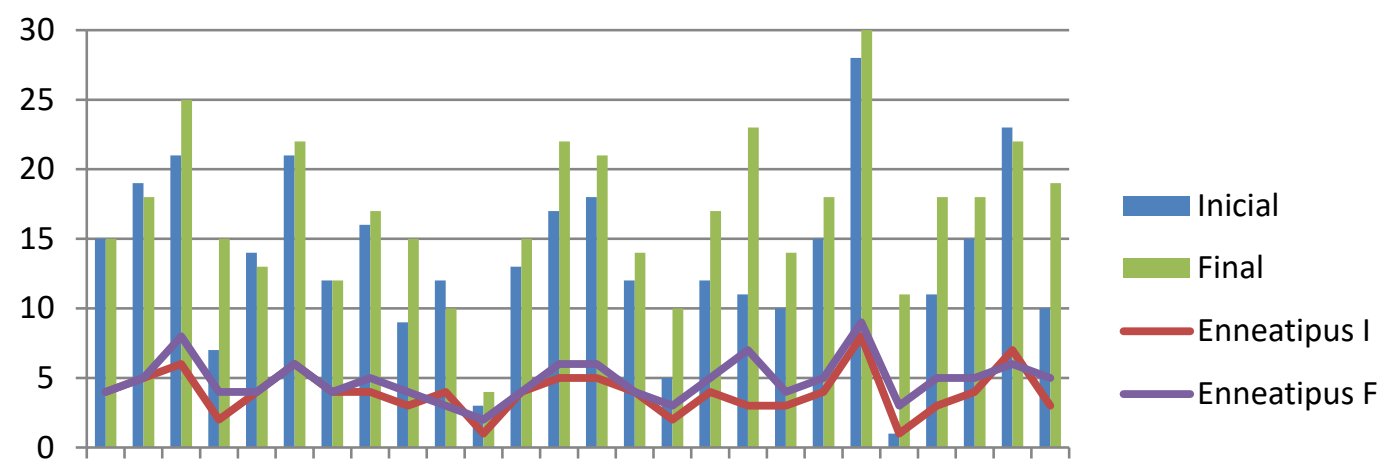

12234456778991011121314151617181920212223242526

Participants

Font. Elaboració pròpia a partir de les dades obtingudes. 
Si observem detingudament el gràfic podem agrupar els participants en tres grans grups:

- Els que han mantingut els seus resultats (com l'1 i el 7), en què es veu que l'enneatipus corresponent també es manté igual.

- Els que han baixat els seus resultats (com el 2, el 5, el 10 i el 25). Els nens 2 i 5 es mantenen dins del mateix nivell (es veu seguint la línia dels enneatipus inicial i final). És a dir, tot i potser no haver obtingut un nombre més alt d'encerts nets, la diferència és tan mínima que es considera que mantenen el ritme habitual. En el cas del 10 i el 25, que són participants que a més d'haver baixat l'enneatipus en comparació amb l'inicial també han reduït el nombre d'encerts nets, hem consultat el full d'assistència i hem vist que han faltat en una o dues sessions pràctiques de tennis taula.

- L'últim grup que pertany a la majoria de participants, concretament 20 de 26: són els que han augmentat el nombre d'encerts i també l'enneatipus. Observar aquests resultats juntament amb l'escala d'apreciació que vam anar emplenant al llarg de les classes pràctiques, ens han servit per adonar-nos que la motivació dels infants i el domini pala-pilota cada dia era més elevat. Sobretot el cas del participant 4, en què el creixement ha estat positiu i l'augment de la concentració a l'aula es va poder veure des de les primeres sessions.

Si comparem aquestes dades amb les del grup de control (figura 6), comprovem que alguns dels participants que no han estat amb la proposta d'introducció del tennis taula també han tingut un petit augment en el tipus d'encerts i l'enneatipus corresponent. Es pot veure com l'increment ha estat més estable que en el grup experimental i, per tant, caldria tenir en compte altres variables com l'evolució dels nens, tant en el seu procés cognitiu com en el maduratiu corresponent a l'etapa en què es troben.

\section{Figura 6}

Encerts nets del grup de control

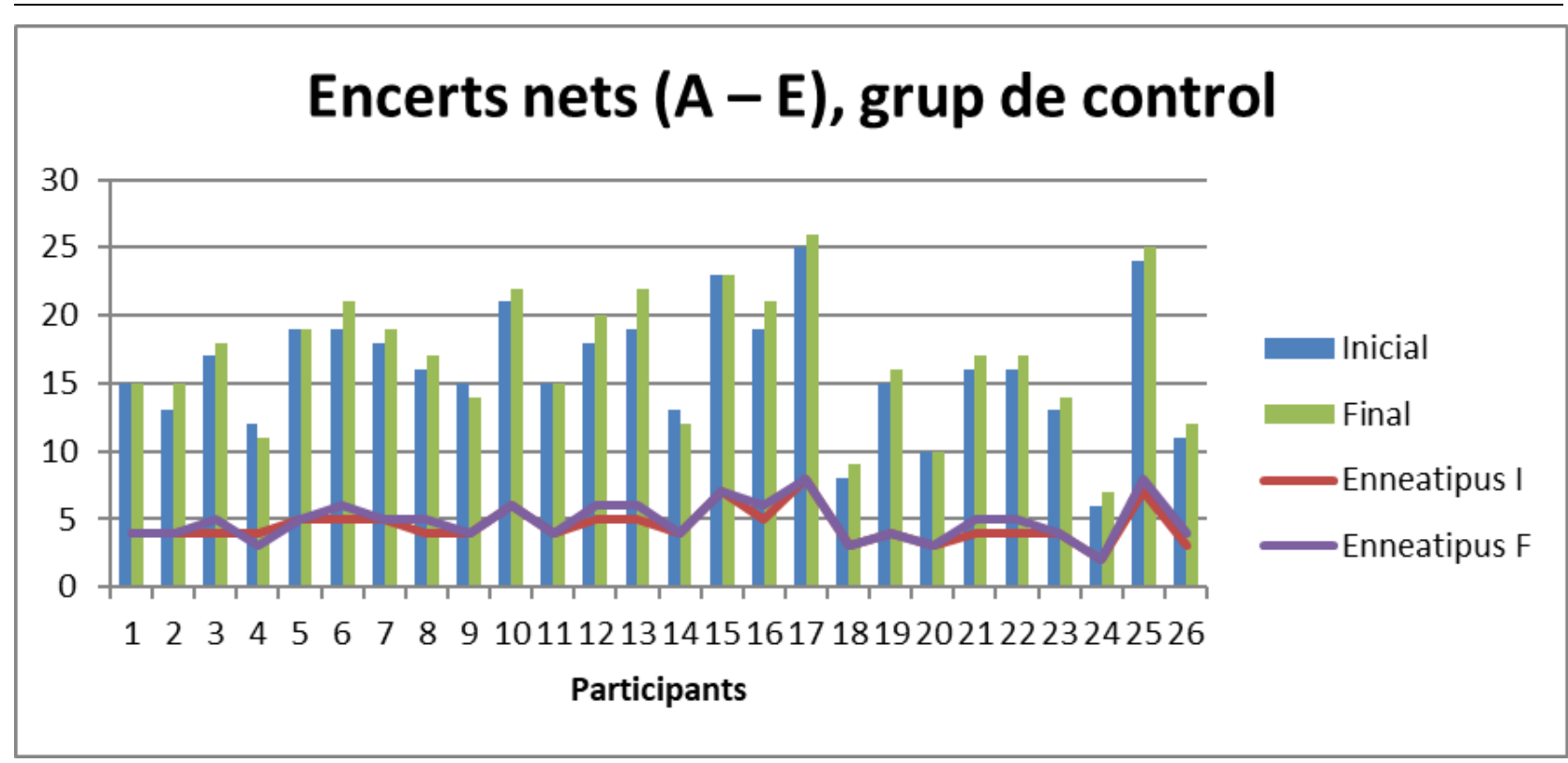

Font. Elaboració pròpia a partir de les dades obtingudes. 
En general, els resultats de l'alumnat del grup de control es mantenen estables; augmenten en un 5,05\%. En aquest grup també hi ha alumnat que destaca pels seus resultats baixos, com els participants 18 i 24 . El primer és un nen amb trastorn de l'espectre autista que rep atenció individualitzada. Els seus resultats, pel que fa a la concentració, es veuen influenciats i molt per sota de la mitjana. El participant 24 és un alumne amb dificultats per seguir el ritme de la classe a causa d'un trastorn de dèficit d'atenció diagnosticat recentment.

Seguint amb l'estudi, ens hem plantejat analitzar l'índex de control de la impulsivitat (ICI) de la mostra participant. Referent a I'ICl, el grup de control en el pretest ha obtingut una puntuació de 2.127 i en el posttest, de 2.266. Això ha suposat un increment del 6,53 \%. En canvi, el grup experimental ha passat de 1.989 punts al pretest a 2.288 al posttest, la qual cosa ha suposat un increment del $15,03 \%$, una diferència percentual de 8,5 punts, doncs.

Pel que fa al grup que ha estat jugant a tennis taula (grup experimental), es pot veure una diferència notable entre el resultat inicial i el final després de fer la proposta d'introducció de la pràctica esportiva durant vuit sessions. També, fixant-nos en els trets generals d'aquest gràfic i comparant-lo amb els resultats dels encerts nets d'aquest grup, podem veure que les dues variables van molt lligades, ja que els participants que havien disminuït el nombre d'encerts segueixen tenint el mateix ICl.

\section{Figura 7}

Comparativa dels resultats de l'ICl del grup experimental

\section{ICl, grup experimental}

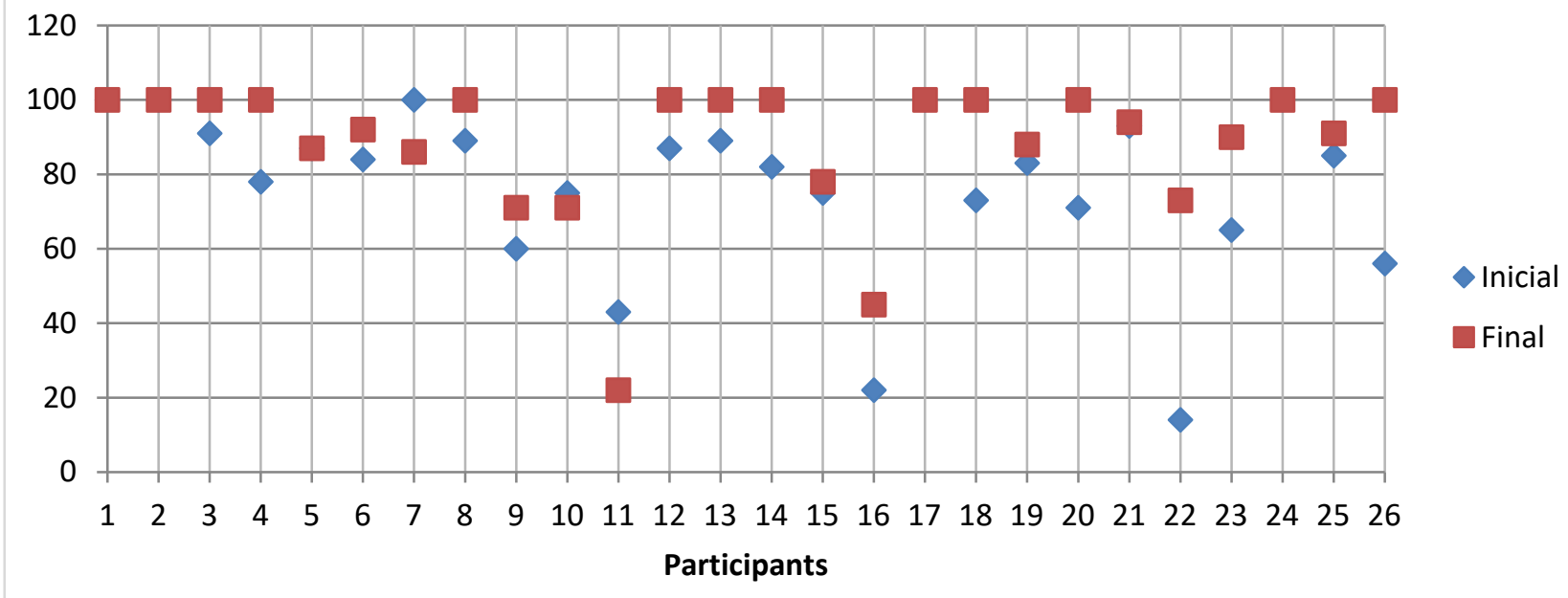

Font. Elaboració pròpia a partir de les dades obtingudes. 
Figura 8

Comparativa dels resultats de l'ICl del grup de control

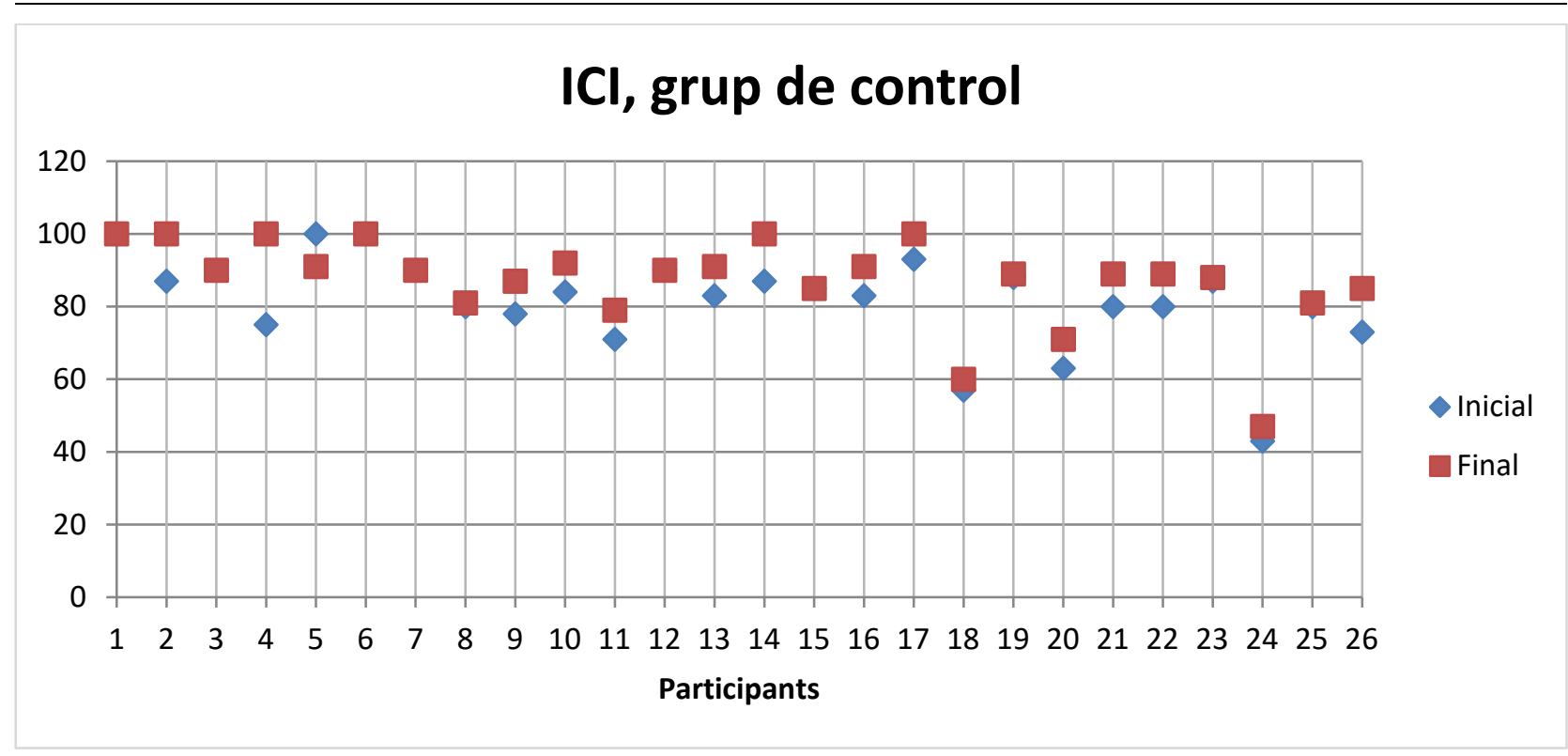

Font. Elaboració pròpia a partir de les dades obtingudes.

Pel que fa als resultats del grup de control en relació amb l'ICl, es pot veure com en la majoria dels casos els participants han millorat la seva impulsivitat però amb uns valors baixos. No ha estat un increment significatiu, fet que va relacionat amb els encerts

\section{Conclusions}

La falta de concentració és un dels problemes més habituals a les aules de l'escola del segle XXI. Ens hem adonat que hi ha molts factors que poden influir en la concentració dels infants i afectar greument el seu rendiment acadèmic. Aquesta investigació està pensada per oferir una millora des de l'àmbit de l'escola a tot l'alumnat. És per això que hem demostrat que incloure el tennis taula en l'horari lectiu pot aportar grans beneficis, tal com s'ha pogut observar. A més a més, és un esport inclusiu que afavoreix compartir un espai d'aprenentatges i de companyonia amb la resta de la classe. Després de dur a terme la recerca i analitzar els resultats, considerem que el nostre objectiu principal durant aquests mesos - millorar la concentració dels nens a partir d'una activitat física motivadora i innovadora per a ells - ha estat assolit.

\subsection{Limitacions i perspectives de futur}

Davant la transferència positiva del tennis taula en la concentració dels infants participants en la recerca, creiem que s'hauria de continuar investigant en el temps i amb una mostra més gran de participants, ampliant la recerca a altres escoles del territori. Es tracta d'una mostra realment petita, que tenia per objectiu convertir-se en una prova pilot per valorar si la pràctica del tennis taula els feia millorar l'atenció. Donats els resultats, i havent incrementat l'atenció en un $28 \%$, creiem oportú analitzar altres esports, de característiques similars i diferents, i fer una comparació entre les diverses pràctiques esportives per veure en quins casos i per quines raons augmenta més o menys l'atenció i la concentració de l'alumnat de cicle inicial de primària. 
Pel que fa al material emprat per a la intervenció educativa, es pot aconseguir a baix cost i podria servir per a alumnes de diferents cursos, ja que no requereix talles ni pesos diferents. Per solucionar la implicació i formació del professorat del centre, creiem que el més adequat seria impartir un curs de formació bàsic per conèixer l'esport i compartir els beneficis que pot aportar als infants. El curs es podria fer durant les últimes setmanes de juny perquè el professorat pugui preparar-se de cara al curs següent $i$ incorporar el tennis taula a les seves programacions $i$ al projecte educatiu del centre.

\section{Referències}

Bisquerra, R. (2016). Metodología de la investigación educativa. Editorial Arco/Libros.

García, J. (2010). Psicología de la atención. Editorial Síntesis.

Guallar, A., i Pons, D. (1994). Concentración y atención en el deporte. A: I. Balaguer (ed.), Entrenamiento Psicológico en el deporte: principios y aplicaciones. Editorial Albatros.

Martí, G., i Marrugat, C. (2014). Avui jugarem a relaxar-nos. Editorial Angle.

Palacios, J., Marchesi, Á., i Coll, C. (2006). Desarrollo psicológico y educación. 1. Psicología Evolutiva. Alianza Editorial.

Thurstone, L., i Yela, M. (2012). CARAS-R. Test de percepción de diferencias (11a ed.). TEA Ediciones.

Weinberg, R. S., i Gould, D. (2010). Fundamentos de Psicología del Deporte y del Ejercicio Físico (4a ed.). Editorial Panamericana. 


\section{Annex 1. Taula de resultats del grup experimental}

\begin{tabular}{|c|c|c|c|c|c|c|c|c|c|c|c|c|c|}
\hline \multicolumn{14}{|c|}{ TEST DE PERCEPCIÓ DE DIFERÈNCIES - GRUP EXPERIMENTAL } \\
\hline \multicolumn{3}{|c|}{ Mesures } & PD & EN & Interpretació & Eficàcia & \multicolumn{3}{|c|}{ Mesures } & PD & EN & Interpretació & Eficàcia \\
\hline \multirow{8}{*}{ A1 } & \multirow{2}{*}{ A } & $\mathrm{I}$ & 15 & 4 & Mitjà & & \multirow{2}{*}{\multicolumn{2}{|c|}{ A }} & 1 & 20 & 5 & Mitjà & \\
\hline & & $\mathbf{F}$ & 15 & 4 & Mitjà & & & & $\mathrm{F}$ & 21 & 5 & Mitjà & \\
\hline & \multirow{2}{*}{ E } & 1 & 0 & 4 & Mitjà & & \multirow{6}{*}{ A14 } & \multirow{2}{*}{$\mathrm{E}$} & 1 & 2 & 7 & Mitjà-alt & \\
\hline & & $F$ & 0 & 4 & Mitjà & I: Eficaç i no impulsiu & & & $F$ & 0 & 4 & Mitjà & I: Eficaç i no impulsiu \\
\hline & \multirow{2}{*}{ A-E } & 1 & 15 & 4 & Mitjà & F: Eficaç i no impulsiu & & \multirow{2}{*}{$A-E$} & 1 & 18 & 5 & Mitjà & F: Eficaç i no impulsiu \\
\hline & & $F$ & 15 & 4 & Mitjà & & & & $\mathrm{F}$ & 21 & 6 & Mitjà & \\
\hline & \multirow{2}{*}{ ICI } & 1 & 100 & 6 & Mitjà & & & \multirow{2}{*}{ ICI } & 1 & 82 & 4 & Mitjà & \\
\hline & & $\mathbf{F}$ & 100 & 6 & Mitjà & & & & $\mathbf{F}$ & 100 & 6 & Mitjà & \\
\hline & $A$ & 1 & 19 & 5 & Mitjà & & & $A$ & 1 & 14 & 4 & Mitjà & \\
\hline & A & $F$ & 18 & 5 & Mitjà & & & A & $\mathrm{F}$ & 16 & 4 & Mitjà & \\
\hline & 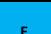 & 1 & 0 & 4 & Mitjà & & & $E$ & 1 & 2 & 7 & Mitjà-alt & \\
\hline$A 2$ & E & $F$ & 0 & 4 & Mitjà & I: Eficaç i no impulsiu & $A 15$ & $\mathrm{E}$ & $\mathrm{F}$ & 2 & 7 & Mitjà-alt & I: Eficaç i no impulsiu \\
\hline${ }^{A 2}$ & A-E & 1 & 19 & 5 & Mitjà & F: Eficaç i no impulsiu & A13 & A-E & 1 & 12 & 4 & Mitjà & F: Eficaç i no impulsiu \\
\hline & $A-E$ & $\mathrm{~F}$ & 18 & 5 & Mitjà & & & $A-E$ & $\mathrm{~F}$ & 14 & 4 & Mitjà & \\
\hline & 9 & 1 & 100 & 6 & Mitjà & & & 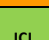 & 1 & 75 & 4 & Mitjà & \\
\hline & $\mathrm{ICI}$ & $\mathbf{F}$ & 100 & 6 & Mitjà & & & $\mathrm{ICl}$ & $\mathrm{F}$ & 78 & 4 & Mitjà & \\
\hline & A & 1 & 22 & 6 & Mitjà & & & . & 1 & 14 & 4 & Mitjà & \\
\hline & A & $\mathbf{F}$ & 25 & 7 & Mitjà-alt & & & $\mathrm{A}$ & $\mathrm{F}$ & 16 & 4 & Mitjà & \\
\hline & & 1 & 1 & 5 & Mitjà & & & $E$ & 1 & 9 & 9 & Molt alt & \\
\hline & E & $F$ & 0 & 4 & Mitjà & I: Eficaç i no impulsiu & A16 & $\mathrm{E}$ & $\mathbf{F}$ & 6 & 8 & Alt & I: Ineficaçi impulsiu \\
\hline A3 & & 1 & 7 & 6 & Mitjà & F: Eficaç i no impulsiu & A16 & & 1 & 5 & 2 & Baix & F: Eficaçi impulsiu \\
\hline & A-E & $\mathrm{F}$ & 15 & 8 & Alt & & & A-E & $\mathrm{F}$ & 10 & 3 & Mitjà-baix & \\
\hline & Ia & 1 & 78 & 5 & Mitjà & & & 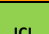 & 1 & 22 & 1 & Molt baix & \\
\hline & $\mathrm{Cl}$ & $F$ & 100 & 6 & Mitjà & & & $\mathrm{ICI}$ & $\mathrm{F}$ & 45 & 2 & Baix & \\
\hline & 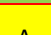 & 1 & 8 & 1 & Molt baix & & & 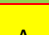 & 1 & 12 & 3 & Mitjà-baix & \\
\hline & A & $\mathrm{F}$ & 15 & 4 & Mitjà & & & A & $\mathrm{F}$ & 17 & 4 & Mitjà & \\
\hline & $E$ & 1 & 1 & 5 & Mitjà & & & $E$ & 1 & 0 & 4 & Mitjà & \\
\hline A4 & E & $F$ & 0 & 4 & Mitjà & I: Ineficaç i no impulsiu & A17 & $\mathrm{E}$ & $\mathrm{F}$ & 0 & 4 & Mitjà & I: Eficaç i no impulsiu \\
\hline A4 & & 1 & 7 & 2 & Baix & F: Eficaç i no impulsiu & A17 & $F$ & 1 & 12 & 4 & Mitjà & F: Eficaç i no impulsiu \\
\hline & $A-E$ & $F$ & 15 & 4 & Mitjà & & & A-E & $\mathrm{F}$ & 17 & 5 & Mitjà & \\
\hline & 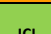 & 1 & 78 & 4 & Mitjà & & & 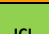 & 1 & 100 & 6 & Mitjà & \\
\hline & ICI & $\mathrm{F}$ & 100 & 6 & Mitjà & & & ICI & $\mathbf{F}$ & 100 & 6 & Mitjà & \\
\hline & A & 1 & 15 & 4 & Mitjà & & & A & 1 & 13 & 3 & Mitjà-baix & \\
\hline & A & $\mathrm{F}$ & 14 & 4 & Mitjà & & & A & $\mathrm{F}$ & 23 & 6 & Mitjà & \\
\hline & E & 1 & 1 & 5 & Mitjà & & & $\mathrm{E}$ & 1 & 2 & 7 & Mitjà-alt & \\
\hline & $\mathrm{E}$ & $\mathrm{F}$ & 1 & 5 & Mitjà & I: Eficaç i no impulsiu & A18 & $\mathrm{E}$ & $\mathrm{F}$ & 0 & 4 & Mitjà & 1: Ineficaç i no impulsiu \\
\hline A5 & A-E & 1 & 14 & 4 & Mitjà & F: Eficaç i no impulsiu & A18 & A-E & 1 & 11 & 3 & Mitjà-baix & F: Eficaç i no impulsiu \\
\hline & $A-E$ & $\mathbf{F}$ & 13 & 4 & Mitjà & & & $A-E$ & $\mathrm{~F}$ & 23 & 7 & Mitjà-alt & \\
\hline & 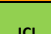 & 1 & 87 & 5 & Mitjà & & & 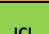 & 1 & 73 & 4 & Mitjà & \\
\hline & $\mathrm{ICI}$ & $F$ & 87 & 5 & Mitjà & & & $\mid \mathrm{ICl}$ & $\mathbf{F}$ & 100 & 6 & Mitjà & \\
\hline & 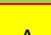 & 1 & 23 & 6 & Mitjà & & & . & 1 & 11 & 2 & Baix & \\
\hline & A & $\mathbf{F}$ & 23 & 6 & Mitjà & & & A & $\mathrm{F}$ & 15 & 4 & Mitjà & \\
\hline & $\varepsilon$ & 1 & 2 & 7 & Mitjà-alt & & & E & 1 & 1 & 5 & Mitjà & \\
\hline$A \in$ & $\mathrm{E}$ & $F$ & 1 & 5 & Mitjà & I: Eficaç i no impulsiu & A19 & $\mathrm{E}$ & $\mathrm{F}$ & 1 & 5 & Mitjà & I: Ineficaç i no impulsiu \\
\hline A6 & & 1 & 21 & 6 & Mitjà & F: Eficaç i no impulsiu & A19 & & 1 & 10 & 3 & Mitjà-baix & F: Eficaç i no impulsiu \\
\hline & $A-E$ & $F$ & 22 & 6 & Mitjà & & & $A-E$ & $F$ & 14 & 4 & Mitjà & \\
\hline & & 1 & 84 & 4 & Mitjà & & & 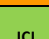 & 1 & 83 & 4 & Mitjà & \\
\hline & ICI & $\mathrm{F}$ & 92 & 6 & Mitjà & & & ICI & $F$ & 88 & 5 & Mitjà & \\
\hline & & 1 & 12 & 3 & Mitjà-baix & & & $A$ & 1 & 18 & 5 & Mitjà & \\
\hline & A & $F$ & 13 & 3 & Mitjà-baix & & & A & $\mathrm{F}$ & 18 & 5 & Mitjà & \\
\hline & & 1 & 0 & 4 & Mitjà & & & $E$ & 1 & 3 & 7 & Mitjà-alt & \\
\hline 7 & E & $F$ & 1 & 5 & Mitjà & I: Eficaç i no impulsiu & & $\mathrm{E}$ & $\mathrm{F}$ & 0 & 4 & Mitjà & I: Eficaç i no impulsiu \\
\hline A7 & $F$ & 1 & 12 & 4 & Mitjà & F: Eficaç i no impulsiu & A20 & $A$ & 1 & 15 & 4 & Mitjà & F: Eficaç i no impulsiu \\
\hline & $A-E$ & $F$ & 12 & 4 & Mitjà & & & $A-E$ & $\mathrm{~F}$ & 18 & 5 & Mitjà & \\
\hline & & 1 & 100 & 6 & Mitjà & & & & 1 & 71 & 4 & Mitjà & \\
\hline & ICI & $F$ & 86 & 5 & Mitjà & & & ICI & $F$ & 100 & 6 & Mitjà & \\
\hline
\end{tabular}




\begin{tabular}{|c|c|c|c|c|c|c|c|c|c|c|c|c|c|}
\hline \multirow{8}{*}{ A8 } & \multirow{2}{*}{ A } & 1 & 17 & 4 & Mitjà & & \multirow{8}{*}{ A21 } & \multirow{2}{*}{ A } & 1 & 29 & 8 & Alt & \\
\hline & & $\mathbf{F}$ & 17 & 4 & Mitjà & & & & $\mathrm{F}$ & 33 & 9 & Molt alt & \\
\hline & \multirow{2}{*}{ E } & 1 & 1 & 6 & Mitjà & & & \multirow{2}{*}{$\mathrm{E}$} & 1 & 1 & 5 & Mitjà & \\
\hline & & $\mathbf{F}$ & 0 & 4 & Mitjà & I: Eficaç i no impulsiu & & & $\mathbf{F}$ & 1 & 5 & Mitjà & I: Eficaç i no impulsiu \\
\hline & \multirow{2}{*}{$A-E$} & 1 & 16 & 4 & Mitjà & F: Eficaç i no impulsiu & & \multirow{2}{*}{$A-E$} & 1 & 28 & 8 & Alt & F: Eficaç i no impulsiu \\
\hline & & $\mathrm{F}$ & 17 & 5 & Mitjà & & & & $\mathrm{F}$ & 32 & 9 & Molt alt & \\
\hline & \multirow{2}{*}{ ICI } & 1 & 89 & 5 & Mitjà & & & \multirow{2}{*}{ ICI } & 1 & 93 & 6 & Mitjà & \\
\hline & & $\mathbf{F}$ & 100 & 6 & Mitjà & & & & $\mathrm{F}$ & 94 & 6 & Mitjà & \\
\hline \multirow{8}{*}{ A9 } & \multirow{2}{*}{ A } & 1 & 12 & 3 & Mitjà & & \multirow{8}{*}{ A22 } & \multirow{2}{*}{ A } & 1 & 4 & 1 & Molt baix & \\
\hline & & $\mathbf{F}$ & 18 & 5 & Mitjà & & & & $\mathbf{F}$ & 13 & 3 & Mitjà-baix & \\
\hline & \multirow{2}{*}{ E } & 1 & 3 & 7 & Mitjà-alt & & & \multirow{2}{*}{ E } & 1 & 3 & 7 & Mitjà-alt & \\
\hline & & $\mathrm{F}$ & 3 & 7 & Mitjà-alt & I: Ineficaç i no impulsiu & & & $\mathrm{F}$ & 2 & 7 & Mitjà-alt & I: Ineficaç i impulsiu \\
\hline & \multirow{2}{*}{ A-E } & 1 & 9 & 3 & Mitjà-baix & F: Eficaç i no impulsiu & & \multirow{2}{*}{ A-E } & 1 & 1 & 1 & Molt baix & F: Eficaç i no impulsiu \\
\hline & & $\mathrm{F}$ & 15 & 4 & Mitjà & & & & $\mathrm{F}$ & 11 & 3 & Mitjà-baix & \\
\hline & (c) & 1 & 60 & 3 & Mitjà-baix & & & 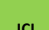 & 1 & 14 & 1 & Molt baix & \\
\hline & W & $\mathbf{F}$ & 71 & 4 & Mitjà & & & W & $\mathrm{F}$ & 73 & 4 & Mitjà & \\
\hline & 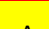 & 1 & 14 & 4 & Mitjà & & & 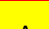 & 1 & 14 & 4 & Mitjà & \\
\hline & 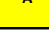 & $\mathbf{F}$ & 12 & 3 & Mitjà-baix & & & $\mathrm{n}$ & $\mathrm{F}$ & 19 & 5 & Mitjà & \\
\hline & $E$ & 1 & 2 & 7 & Mitjà-alt & & & $E$ & 1 & 2 & 7 & Mitjà-alt & \\
\hline A10 & 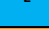 & $\mathbf{F}$ & 2 & 7 & Mitjà-alt & I: Eficaç i no impulsiu & $A 23$ & 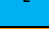 & $\mathbf{F}$ & 1 & 5 & Mitjà & I: Ineficaç i impulsiu \\
\hline Alv & $A$ & 1 & 12 & 4 & Mitjà & F: Ineficaç i no impulsiu & $A<S$ & $A-F$ & 1 & 11 & 3 & Mitjà-baix & F: Eficaç i no impulsiu \\
\hline & $A-E$ & $\mathrm{~F}$ & 10 & 3 & Mitjà-baix & & & $A-E$ & $\mathrm{~F}$ & 18 & 5 & Mitjà & \\
\hline & 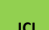 & 1 & 75 & 4 & Mitjà & & & IC & 1 & 65 & 3 & Mitjà-baix & \\
\hline & (1) & $\mathbf{F}$ & 71 & 4 & Mitjà & & & W & $\mathrm{F}$ & 90 & 5 & Mitjà & \\
\hline & A & $\mathrm{I}$ & 5 & 1 & Molt baix & & & A & 1 & 15 & 4 & Mitjà & \\
\hline & A & $\mathbf{F}$ & 11 & 2 & Baix & & & H & $\mathbf{F}$ & 18 & 5 & Mitjà & \\
\hline & $E$ & 1 & 2 & 7 & Mitjà-alt & & & $E$ & 1 & 0 & 4 & Mitjà & \\
\hline A11 & 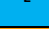 & $\mathbf{F}$ & 7 & 8 & Alt & I: Ineficaç i impulsiu & A24 & 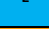 & $\mathbf{F}$ & 0 & 4 & Mitjà & I: Eficaç i no impulsiu \\
\hline AII & $A$ & 1 & 3 & 1 & Molt baix & F: Ineficaç i impulsiu & A24 & F & 1 & 15 & 4 & Mitjà & F: Eficaç i no impulsiu \\
\hline & $A-E$ & $F$ & 4 & 2 & Baix & & & $A-E$ & $\mathrm{~F}$ & 18 & 5 & Mitjà & \\
\hline & 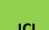 & 1 & 43 & 2 & Baix & & & 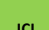 & 1 & 100 & 6 & Mitjà & \\
\hline & (I) & $\mathrm{F}$ & 22 & 1 & Molt baix & & & (CI & $F$ & 100 & 6 & Mitjà & \\
\hline & $A$ & 1 & 14 & 4 & Mitjà & & & A & 1 & 25 & 7 & Mitjà-alt & \\
\hline & $\mathrm{A}^{\mathrm{A}}$ & $\mathbf{F}$ & 15 & 4 & Mitjà & & & $\mathrm{A}$ & $F$ & 23 & 6 & Mitjà & \\
\hline & $E$ & 1 & 1 & 5 & Mitjà & & & $E$ & 1 & 2 & 7 & Mitjà-alt & \\
\hline A12 & c & $\mathbf{F}$ & 0 & 4 & Mitjà & I: Eficaç i no impulsiu & $A 25$ & r & $F$ & 1 & 5 & Mitjà & I: Eficaç i no impulsiu \\
\hline A12 & 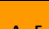 & 1 & 13 & 4 & Mitjà & F: Eficaç i no impulsiu & $A<S$ & 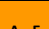 & 1 & 23 & 7 & Mitjà-alt & F: Eficaç i no impulsiu \\
\hline & $A-L$ & $\mathbf{F}$ & 15 & 4 & Mitjà & & & A. & $\mathrm{F}$ & 22 & 6 & Mitjà & \\
\hline & 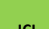 & 1 & 87 & 5 & Mitjà & & & 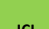 & 1 & 85 & 5 & Mitjà & \\
\hline & $\mathrm{Cl}$ & $F$ & 100 & 6 & Mitjà & & & $\mathrm{ICI}$ & $\mathbf{F}$ & 91 & 5 & Mitjà & \\
\hline & 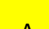 & 1 & 18 & 5 & Mitjà & & & 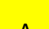 & 1 & 14 & 4 & Mitjà & \\
\hline & A & $\mathrm{F}$ & 22 & 6 & Mitjà & & & A & $\mathrm{F}$ & 19 & 5 & Mitjà & \\
\hline & $E$ & 1 & 1 & 5 & Mitjà & & & $E$ & 1 & 4 & 8 & Alt & \\
\hline$A 13$ & $\mathrm{E}$ & $F$ & 0 & 4 & Mitjà & I: Eficaç i no impulsiu & $A 26$ & $\mathrm{E}$ & $\mathrm{F}$ & 0 & 4 & Mitjà & I: Ineficaç i impulsiu \\
\hline 410 & A-E & 1 & 17 & 5 & Mitjà & F: Eficaç i no impulsiu & ACb & $A-F$ & 1 & 10 & 3 & Mitjà-baix & F: Eficaç i no impulsiu \\
\hline & A. & $\mathbf{F}$ & 22 & 6 & Mitjà & & & $A-L$ & $\mathrm{~F}$ & 19 & 5 & Mitjà & \\
\hline & ICI & 1 & 89 & 5 & Mitjà & & & ICI & 1 & 56 & 2 & Baix & \\
\hline & KI & $\mathrm{F}$ & 100 & 6 & Mitjà & & & & $F$ & 100 & 6 & Mitjà & \\
\hline
\end{tabular}




\section{Annex 2. Taula de resultats del grup de control}

\begin{tabular}{|c|c|c|c|c|c|c|c|c|c|c|c|c|c|}
\hline \multicolumn{14}{|c|}{ TEST DE PERCEPCIÓ DE DIFERÈNCIES, GRUP DE CONTROL } \\
\hline \multicolumn{3}{|c|}{ Mesures } & PD & EN & Interpretació & \begin{tabular}{|c|} 
Eficàcia \\
\end{tabular} & \multicolumn{3}{|c|}{ Mesures } & PD & EN & Interpretació & Eficàcia \\
\hline \multirow{8}{*}{ A1 } & \multirow{2}{*}{ A } & 1 & 15 & 4 & Mitjà & & \multirow{2}{*}{\multicolumn{2}{|c|}{ A }} & 1 & 14 & 4 & Mitjà & \\
\hline & & $F$ & 15 & 4 & Mitjà & & & & $\mathrm{F}$ & 12 & 3 & Mitjà-baix & \\
\hline & \multirow{2}{*}{ E } & 1 & 0 & 4 & Mitjà & & \multirow{6}{*}{ A14 } & \multirow{2}{*}{$\mathrm{E}$} & 1 & 1 & 5 & Mitjà & \\
\hline & & $F$ & 0 & 4 & Mitjà & I: Eficaç i no impulsiu & & & $F$ & 0 & 4 & Mitjà & I: Eficaç i no impulsiu \\
\hline & \multirow{2}{*}{ A-E } & 1 & 15 & 4 & Mitjà & F: Eficaç i no impulsiu & & \multirow{2}{*}{$A-E$} & 1 & 13 & 4 & Mitjà & F: Eficaç i no impulsiu \\
\hline & & $F$ & 15 & 4 & Mitjà & & & & $\mathrm{F}$ & 12 & 4 & Mitjà & \\
\hline & \multirow{2}{*}{ ICI } & 1 & 100 & 6 & Mitjà & & & \multirow{2}{*}{ ICI } & 1 & 87 & 5 & Mitjà & \\
\hline & & $F$ & 100 & 6 & Mitjà & & & & $F$ & 100 & 6 & Mitjà & \\
\hline & 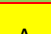 & 1 & 14 & 4 & Mitjà & & & 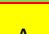 & 1 & 25 & 7 & Mitjà-alt & \\
\hline & A & $\mathrm{F}$ & 15 & 4 & Mitjà & & & A & $\mathrm{F}$ & 25 & 7 & Mitjà-alt & \\
\hline & $=$ & 1 & 1 & 5 & Mitjà & & & $E$ & 1 & 2 & 7 & Mitjà-alt & \\
\hline & E & $F$ & 0 & 4 & Mitjà & I: Eficaç i no impulsiu & A15 & $\mathrm{E}$ & $\mathrm{F}$ & 2 & 7 & Mitjà-alt & I: Eficaç i no impulsiu \\
\hline A2 & A & 1 & 13 & 4 & Mitjà & F: Eficaç i no impulsiu & A15 & $A-F$ & 1 & 23 & 7 & Mitjà-alt & F: Eficaç i no impulsiu \\
\hline & $A-E$ & $F$ & 15 & 4 & Mitjà & & & A-E & $\mathrm{F}$ & 23 & 7 & Mitjà-alt & \\
\hline & 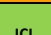 & 1 & 87 & 5 & Mitjà & & & 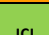 & 1 & 85 & 5 & Mitjà & \\
\hline & $\mathbf{I C I}$ & $F$ & 100 & 6 & Mitjà & & & $\mid \mathbf{I C I}$ & $\mathrm{F}$ & 85 & 5 & Mitjà & \\
\hline & 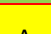 & 1 & 18 & 5 & Mitjà & & & 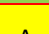 & 1 & 21 & 5 & Mitjà & \\
\hline & A & $F$ & 19 & 5 & Mitjà & & & A & $\mathrm{F}$ & 22 & 6 & Mitjà & \\
\hline & E & 1 & 1 & 7 & Mitjà-alt & & & $E$ & 1 & 2 & 7 & Mitjà-alt & \\
\hline 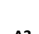 & E & $\mathbf{F}$ & 1 & 5 & Mitjà & I: Eficaç i no impulsiu & H & E & $\mathrm{F}$ & 1 & 5 & Mitjà & I: Eficaç i no impulsiu \\
\hline A3 & & 1 & 17 & 4 & Mitjà & F: Eficaç i no impulsiu & A16 & & 1 & 19 & 5 & Mitjà & F: Eficaç i no impulsiu \\
\hline & $A-E$ & $F$ & 18 & 5 & Mitjà & & & A-E & $\mathrm{F}$ & 21 & 6 & Mitjà & \\
\hline & 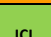 & 1 & 90 & 5 & Mitjà & & & 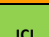 & 1 & 83 & 4 & Mitjà & \\
\hline & & $\mathbf{F}$ & 90 & 5 & Mitjà & & & $\mathrm{ICl}$ & $\mathrm{F}$ & 91 & 5 & Mitjà & \\
\hline & 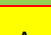 & 1 & 14 & 4 & Mitjà & & & 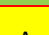 & 1 & 26 & 7 & Mitjà-alt & \\
\hline & A & $F$ & 11 & 2 & Baix & & & A & $\mathrm{F}$ & 26 & 7 & Mitjà-alt & \\
\hline & E & 1 & 2 & 7 & Mitjà-alt & & & $E$ & 1 & 1 & 5 & Mitjà & \\
\hline a & $\mathrm{E}$ & $F$ & 0 & 4 & Mitjà & I: Eficaç i no impulsiu & A17 & $\mathrm{E}$ & $\mathrm{F}$ & 0 & 4 & Mitjà & I: Eficaç i no impulsiu \\
\hline A4 & A & 1 & 12 & 4 & Mitjà & F: Eficaç i no impulsiu & A17 & $A$ & 1 & 25 & 8 & Alt & F: Eficaç i no impulsiu \\
\hline & $A-E$ & $F$ & 11 & 3 & Mitjà-baix & & & $A-E$ & $\mathrm{~F}$ & 26 & 8 & Alt & \\
\hline & 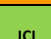 & 1 & 75 & 4 & Mitjà & & & 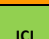 & 1 & 93 & 6 & Mitjà & \\
\hline & $\mathbf{I C l}$ & $\mathbf{F}$ & 100 & 6 & Mitjà & & & $\mid \mathrm{ICl}$ & $\mathrm{F}$ & 100 & 6 & Mitjà & \\
\hline & $A$ & 1 & 19 & 5 & Mitjà & & & A & 1 & 11 & 2 & Baix & \\
\hline & A & $\mathbf{F}$ & 20 & 5 & Mitjà & & & A & $\mathrm{F}$ & 12 & 3 & Mitjà-baix & \\
\hline & 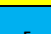 & 1 & 0 & 4 & Mitjà & & & 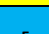 & 1 & 3 & 7 & Mitjà-alt & \\
\hline & $\mathrm{E}$ & $\mathrm{F}$ & 1 & 5 & Mitjà & I: Eficaç i no impulsiu & & $\mathrm{E}$ & $\mathrm{F}$ & 3 & 7 & Mitjà-alt & I: Ineficaç i impulsiu \\
\hline A5 & A-E & 1 & 19 & 5 & Mitjà & F: Eficaç i no impulsiu & A18 & A-E & 1 & 8 & 3 & Mitjà-baix & F: Ineficaç i impulsiu \\
\hline & $A-E$ & $\mathrm{~F}$ & 19 & 5 & Mitjà & & & $A-E$ & $F$ & 9 & 3 & Mitjà-baix & \\
\hline & 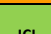 & 1 & 100 & 6 & Mitjà & & & 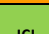 & 1 & 57 & 3 & Mitjà-baix & \\
\hline & ICI & $\mathbf{F}$ & 91 & 5 & Mitjà & & & $\mid \mathrm{ICI}$ & $F$ & 60 & 3 & Mitjà-baix & \\
\hline & A & 1 & 19 & 5 & Mitjà & & & $A$ & 1 & 16 & 4 & Mitjà & \\
\hline & A & $\mathrm{F}$ & 21 & 5 & Mitjà & & & A & $\mathrm{F}$ & 17 & 4 & Mitjà & \\
\hline & E & 1 & 0 & 4 & Mitjà & & & E & 1 & 1 & 5 & Mitjà & \\
\hline & E & $F$ & 0 & 4 & Mitjà & I: Eficaç i no impulsiu & & $\mathrm{E}$ & $\mathrm{F}$ & 1 & 5 & Mitjà & I: Eficaç i no impulsiu \\
\hline A6 & 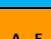 & 1 & 19 & 5 & Mitjà & F: Eficaç i no impulsiu & A19 & 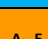 & 1 & 15 & 4 & Mitjà & F: Eficaç i no impulsiu \\
\hline & $A-E$ & $\mathrm{~F}$ & 21 & 6 & Mitjà & & & A-E & $\mathrm{F}$ & 16 & 4 & Mitjà & \\
\hline & 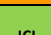 & 1 & 100 & 6 & Mitjà & & & 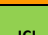 & 1 & 88 & 5 & Mitjà & \\
\hline & $\mathrm{ICI}$ & $F$ & 100 & 6 & Mitjà & & & $\mid \mathrm{ICl}$ & $F$ & 89 & 5 & Mitjà & \\
\hline & & 1 & 19 & 5 & Mitjà & & & 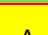 & 1 & 13 & 3 & Mitjà-baix & \\
\hline & A & $F$ & 20 & 5 & Mitjà & & & A & $\mathrm{F}$ & 12 & 3 & Mittà-baix & \\
\hline & $\mathrm{E}$ & 1 & 1 & 5 & Mitjà & & & $\mathrm{E}$ & 1 & 3 & 7 & Mitjjà-alt & \\
\hline 77 & E & $F$ & 1 & 5 & Mitjà & I: Eficaç i no impulsiu & 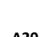 & $\mathrm{E}$ & $F$ & 2 & 7 & Mitjà-alt & I: Ineficaçi impulsiu \\
\hline$A^{\prime}$ & $A=$ & 1 & 18 & 5 & Mitjà & F: Eficaç i no impulsiu & A20 & F & 1 & 10 & 3 & Mitjà-baix & F: Eficaç i no impulsiu \\
\hline & $A-E$ & $F$ & 19 & 5 & Mitjà & & & $A-E$ & $\mathrm{~F}$ & 10 & 3 & Mitjà-baix & \\
\hline & 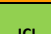 & 1 & 90 & 5 & Mitjà & & & 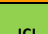 & 1 & 63 & 3 & Mitjà-baix & \\
\hline & $\mathbf{I C I}$ & $F$ & 90 & 5 & Mitjà & & & $\mid \mathrm{ICI}$ & $\mathrm{F}$ & 71 & 4 & Mitjà & \\
\hline
\end{tabular}




\begin{tabular}{|c|c|c|c|c|c|c|c|c|c|c|c|c|c|}
\hline \multirow{8}{*}{ A8 } & \multirow{2}{*}{ A } & 1 & 18 & 5 & Mitjà & & \multirow{8}{*}{ A21 } & \multirow{2}{*}{ A } & 1 & 18 & 5 & Mitjà & \\
\hline & & $F$ & 19 & 5 & Mitjà & & & & $F$ & 18 & 5 & Mitjà & \\
\hline & \multirow{2}{*}{ E } & 1 & 2 & 7 & Mitjà-alt & & & \multirow{2}{*}{ E } & 1 & 2 & 7 & Mitjà-alt & \\
\hline & & $F$ & 2 & 7 & Mitjà-alt & I: Eficaç i no impulsiu & & & $\mathrm{F}$ & 1 & 5 & Mitjà & I: Eficaç i no impulsiu \\
\hline & \multirow{2}{*}{$A-E$} & 1 & 16 & 4 & Mitjà & F: Eficaç i no impulsiu & & \multirow{2}{*}{ A-E } & 1 & 16 & 4 & Mitjà & F: Eficaç i no impulsiu \\
\hline & & $\mathbf{F}$ & 17 & 5 & Mitjà & & & & $\mathrm{F}$ & 17 & 5 & Mitjà & \\
\hline & \multirow{2}{*}{ ICI } & 1 & 80 & 4 & Mitjà & & & \multirow{2}{*}{$\mathbf{I C I}$} & 1 & 80 & 4 & Mitjà & \\
\hline & & $F$ & 81 & 4 & Mitjà & & & & $\mathrm{F}$ & 89 & 5 & Mitjà & \\
\hline \multirow{8}{*}{ A9 } & \multirow{2}{*}{ A } & 1 & 17 & 4 & Mitjà & & \multirow{8}{*}{ A22 } & \multirow{2}{*}{ A } & 1 & 18 & 5 & Mitjà & \\
\hline & & $\mathrm{F}$ & 15 & 4 & Mitjà & & & & $\mathrm{F}$ & 18 & 5 & Mitjà & \\
\hline & \multirow{2}{*}{ E } & 1 & 2 & 7 & Mitjà-alt & & & \multirow{2}{*}{ E } & 1 & 2 & 7 & Mitjà-alt & \\
\hline & & $F$ & 1 & 5 & Mitjà & I: Eficaç i no impulsiu & & & $\mathrm{F}$ & 1 & 5 & Mitjà & I: Eficaç i no impulsiu \\
\hline & \multirow{2}{*}{ A-E } & 1 & 15 & 4 & Mitjà & F: Eficaç i no impulsiu & & \multirow{2}{*}{ A-E } & 1 & 16 & 4 & Mitjà & F: Eficaç i no impulsiu \\
\hline & & $F$ & 14 & 4 & Mitjà & & & & $\mathrm{F}$ & 17 & 5 & Mitjà & \\
\hline & 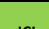 & 1 & 78 & 4 & Mitjà & & & 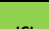 & 1 & 80 & 4 & Mitjà & \\
\hline & $\mathrm{ICl}$ & $\mathbf{F}$ & 87 & 5 & Mitjà & & & $\mathrm{ICl}$ & $\mathrm{F}$ & 89 & 5 & Mitjà & \\
\hline & A & 1 & 23 & 6 & Mitjà & & & $A$ & 1 & 14 & 4 & Mitjà & \\
\hline & A & $F$ & 23 & 6 & Mitjà & & & A & $\mathrm{F}$ & 15 & 4 & Mitjà & \\
\hline & $\mathrm{E}$ & 1 & 2 & 7 & Mitjà-alt & & & $E$ & 1 & 1 & 5 & Mitjà & \\
\hline A1 & E & $F$ & 1 & 5 & Mitjà & I: Eficaç i no impulsiu & $A 23$ & $\mathrm{E}$ & $\mathrm{F}$ & 1 & 5 & Mitjà & I: Eficaç i no impulsiu \\
\hline A10 & $A-E$ & 1 & 21 & 6 & Mitjà & F: Eficaç i no impulsiu & A<3 & $A-E$ & 1 & 13 & 4 & Mitjà & F: Eficaç i no impulsiu \\
\hline & $A-E$ & $F$ & 22 & 6 & Mitjà & & & $A-E$ & $\mathrm{~F}$ & 14 & 4 & Mitjà & \\
\hline & 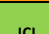 & 1 & 84 & 4 & Mitjà & & & 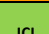 & 1 & 87 & 5 & Mitjà & \\
\hline & $\mathrm{ICI}$ & $F$ & 92 & 6 & Mitjà & & & $\mathrm{ICl}$ & $\mathrm{F}$ & 88 & 5 & Mitjà & \\
\hline & 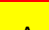 & 1 & 18 & 5 & Mitjà & & & 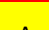 & 1 & 10 & 2 & Baix & \\
\hline & A & $\mathrm{F}$ & 17 & 4 & Mitjà & & & A & $\mathbf{F}$ & 11 & 2 & Baix & \\
\hline & $F$ & 1 & 3 & 7 & Mitjà-alt & & & $E$ & 1 & 4 & 8 & Alt & \\
\hline A11 & $\mathrm{E}$ & $F$ & 2 & 7 & Mitjà-alt & & $A 24$ & $\mathrm{E}$ & $\mathrm{F}$ & 4 & 8 & Alt & I: Ineficaç i impulsiu \\
\hline A11 & $A-F$ & 1 & 15 & 4 & Mitjà & I: Eficaç i no impulsiu & $A<4$ & $A-F$ & 1 & 6 & 2 & Baix & F: Ineficaç i impulsiu \\
\hline & $A-E$ & $F$ & 15 & 4 & Mitjà & F: Eficaç i no impulsiu & & $A-E$ & $\mathrm{~F}$ & 7 & 2 & Baix & \\
\hline & 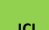 & 1 & 71 & 4 & Mitjà & & & 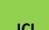 & 1 & 43 & 2 & Baix & \\
\hline & $\mathrm{ICl}$ & $F$ & 79 & 4 & Mitjà & & & $\mathrm{ICl}$ & $\mathrm{F}$ & 47 & 2 & Baix & \\
\hline & . & 1 & 19 & 5 & Mitjà & & & 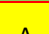 & 1 & 27 & 8 & Alt & \\
\hline & A & $F$ & 21 & 5 & Mitjà & & & A & $\mathrm{F}$ & 28 & 8 & Alt & \\
\hline & $E$ & 1 & 1 & 5 & Mitjà & & & E & 1 & 3 & 7 & Mitjà-alt & \\
\hline A12 & $\mathrm{E}$ & $F$ & 1 & 5 & Mitjà & I: Eficaç i no impulsiu & $A 25$ & $\mathrm{E}$ & $\mathrm{F}$ & 3 & 7 & Mitjà-alt & I: Eficaç i no impulsiu \\
\hline A12 & $F$ & 1 & 18 & 5 & Mitjà & F: Eficaç i no impulsiu & A25 & $A$ & 1 & 24 & 7 & Mitjà-alt & F: Eficaç i no impulsiu \\
\hline & $A-E$ & $F$ & 20 & 6 & Mitjà & & & $A-E$ & $\mathrm{~F}$ & 25 & 8 & Alt & \\
\hline & S & 1 & 90 & 5 & Mitjà & & & , & 1 & 80 & 4 & Mitjà & \\
\hline & $\mid \mathrm{ICl}$ & $F$ & 90 & 5 & Mitjà & & & $\mid \mathrm{ICl}$ & $F$ & 81 & 4 & Mitjà & \\
\hline & A & 1 & 21 & 5 & Mitjà & & & A & 1 & 13 & 3 & Mitjà-baix & \\
\hline & A & $F$ & 23 & 6 & Mitjà & & & A & $\mathrm{F}$ & 13 & 3 & Mitjà-baix & \\
\hline & $E$ & 1 & 2 & 7 & Mitjà-alt & & & $E$ & 1 & 2 & 7 & Mitjà-alt & \\
\hline$A 13$ & & $F$ & 1 & 5 & Mitjà & I: Eficaç i no impulsiu & $A 26$ & & $\mathrm{~F}$ & 1 & 5 & Mitjà & I: Eficaç i no impulsiu \\
\hline A13 & A-E & 1 & 19 & 5 & Mitjà & F: Eficaç i no impulsiu & ACb & $A-E$ & 1 & 11 & 3 & Mitjà-baix & F: Eficaç i no impulsiu \\
\hline & A. & $\mathbf{F}$ & 22 & 6 & Mitjà & & & $A-L$ & $\mathrm{~F}$ & 12 & 4 & Mitjà & \\
\hline & 19 & 1 & 83 & 4 & Mitjà & & & 19 & 1 & 73 & 4 & Mitjà & \\
\hline & & $\mathrm{F}$ & 91 & 5 & Mitjà & & & & $\mathrm{F}$ & 85 & 5 & Mitjà & \\
\hline
\end{tabular}

